\title{
PENSAR A BIOPOLÍTICA A PARTIR DA TEOLOGIA: CONTRIBUIÇÕES DE AGAMBEN
}

\author{
Alex G. Pin'1 \\ Universidade de Brasília (UnB) \\ (iD) https://orcid.org/0000-0001-8703-0963 \\ E-mail: alexgpin@live.com
}

\section{RESUMO:}

A publicação de 2007, Homo Sacer II, 2, Il Regno e la Gloria, constitui marco na obra agambenana. Por um lado, o projeto Homo Sacer, que tinha por objetivo a genealogia do poder político, ascende a nova e decisiva dimensão: desvela o paradigma da teologia econômica, que permite explicar com maior precisão a articulação entre o reino e o governo, e os alcances do diagnóstico biopolítico. Por outro, Agamben crê haver encontrado nesse livro o arcano do poder: a glória. A concepção da política como administração, óıðovouía, governo no qual a onipresença da economia expande-se por todos os aspectos da vida social é índice do movimento que alcança na glória sua máxima expressão.

PALAVRAS-CHAVE: Agamben; Biopolítica; Teologia.

\section{THINKING BIOPOLITICS FROM THEOLOGY: CONTRIBUTIONS OF AGAMBEN}

\begin{abstract}
:
The 2007 publication, Homo Sacer II, 2, Il Regno e la Glória, is milestone in agambenana work. On the one hand, the project Homo Sacer that was to the genealogy of political power rides to new and decisive dimension: the paradigm of economic theology, which helps to explain more precisely the relationship between the kingdom and the government, and the reaches the biopolitical diagnosis. On the other hand, Agamben believes to have found this book the arcana of power: the glory. The conception of politic as administration, óxovouía, government in which the omnipresence of the economy expands for all aspects of social life is index-cloaking movement that reaches the glory its maximum expression.
\end{abstract}

KEYWORDS: Agamben; Biopolitic; Theology.

1 Doutorando em Bioética na Universidade de Brasília (UnB), Brasília - DF, Brasil.

PIN, Alex G. Pensar a biopolítica a partir da teologia: contribuições de Agamben. Griot : Revista de Filosofia, Amargosa - BA, v.18, n.2, p.187-197, dezembro, 2018. 


\section{Introdução}

A publicação de 2007, Homo Sacer II, 2, Il Regno e la Gloria, constitui marco na obra agambenana. Por um lado, o projeto Homo Sacer, que tinha por objetivo a genealogia do poder político, ascende a nova e decisiva dimensão: o paradigma da teologia econômica, que permite explicar com maior precisão a articulação entre o reino e o governo, e os alcances do diagnóstico biopolítico. Por outro, Agamben pensa ter encontrado o arcano do poder: a glória. A concepção da política como administração, ỏıovouía, governo no qual a onipresença da economia expande-se por todos os aspectos da vida social é índice do movimento que alcança na glória sua máxima expressão.

O segredo último do poder se encontra, precisamente, na operação de glorificação que está intimamente relacionada com a óıðovouía. A glória funda e sustenta o poder mediante estratégia de encobrimento que oculta e captura o vazio, o desvelamento da ausência de fundamentação própria do político. Porém, o que é a glória? Como se deve entender a utilização deste 'laboratório teológico'? Qual a relação entre teologia e política? É possível encontrar na obra de Agamben algo mais que a descrição dos dispositivos jurídicos e econômicos que controlam a política? $\mathrm{E}$ ainda mais - caso seja possível respondê-lo - será possível que a análise da glória permita encontrar algum tipo de proposta que possibilite fazer frente ao diagnóstico biopolítico?

A chave para tentar responder a essas interrogações consiste em desvelar o funcionamento do laboratório teológico agambenano. A expressão é do nosso filósofo,

\footnotetext{
O dispositivo da oikonomia trinitária pode constituir um laboratório privilegiado para observar o funcionamento e a articulação - ao mesmo tempo interna e externa - da máquina governamental. E isso se deve ao fato de que nele os instrumentos - ou as polaridades - com que se articula a máquina aparecem, por assim dizer, em sua forma paradigmática (AGAMBEN, 2011: 9).
}

A análise dos dispositivos teológicos permite a Agamben observar a lógica mais extrema dos conceitos políticos, expondo assim suas características mais peculiares. Porém, esse recurso não se limita a fazer possível a avaliação adequada do poder, mas também oferece as bases para postular certas delimitações para a proposta de resistência frente à legalização e economização biopolítica.

Para Agamben, não há hoje poder algum na terra que seja legítimo, e os poderosos do mundo estão eles próprios convencidos da ilegitimidade. A legalização e a economização completa das relações humanas, a confusão entre o que se pode acreditar - a esperança e o amor -, e o que se é obrigado a fazer ou não, a dizer ou não, marcam não só a crise da lei e do Estado, mas também, e especialmente, a da Igreja (AGAMBEN, 2010: 18).

Os resultados da análise permitem desativar e profanar os dispositivos biopolíticos. Deter-se no tratamento agambenano da categoria teológica da glória torna inteligível tanto o funcionamento do procedimento de diagnóstico como os 
recursos que motivam as características de sua proposta alternativa centrada na ideia de vida eterna e, portanto, também caracterizada em termos teológicos.

\section{O kabôd e a $\delta$ ó $\xi \alpha$}

Ao finalizar o capítulo VII de Homo Sacer II, 2, Agamben explica que seu interesse central não está em responder o que é a glória ou o poder, mas indagar sobre a relação entre ambos (AGAMBEN, 2011: 217). Não se trata, pois, de perguntar sobre a glória, mas sobre a glorificação. Com este objetivo, o capítulo VIII empreende a arqueologia da glória.

A primeira constatação da investigação é que se verifica importante transformação no conceito de glória na passagem da terminologia veterotestamentária hebraica kabôd para a neotestamentária grega $\delta o ́ \xi \alpha$. O kabôd colocava acento na glória como ser divino, ao ser traduzido para $\delta$ ó $\alpha$ desloca seu significado para a práxis divina - portanto, trinitária. A glória passa a ser entendida principalmente como a operação de glorificação que designa as relações na economia trinitária ("E Jesus disse: Agora o Filho do homem é glorificado, e Deus é glorificado nele. Sendo Deus glorificado nele, também Deus o glorificará nele mesmo" Jo 13, 31 $32)$.

O que era, sobretudo, elemento externo a Deus, e que significava sua presença, é agora, de acordo com o novo contexto teológico em que se situa, a expressão das

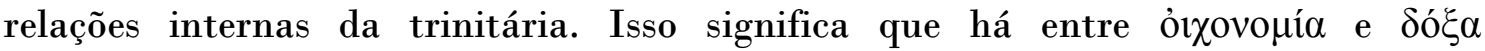
circularidade constitutiva, e não é possível entender a teologia econômica se, ao mesmo tempo, não for identificada essa circularidade.

Assim como a teologia cristã havia transformado dinamicamente o monoteísmo bíblico, opondo dialeticamente, em seu interior, a unidade da substância

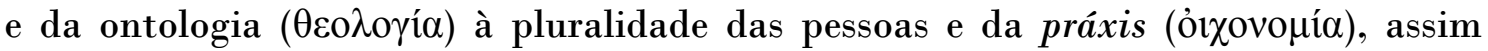

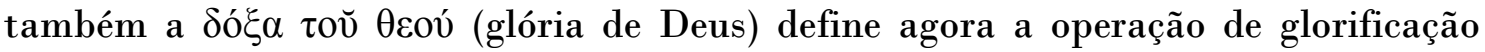
recíproca entre o Pai e o Filho (e, mais em geral, entre as três pessoas). A economia trinitária é constitutivamente economia da glória (AGAMBEN, 2011: 223).

A minuciosa análise da reflexão teológica sobre essa categoria, desde os Padres da Igreja a nossos dias, permite a Agamben postular vinculo perene e indissolúvel entre $\delta o ́ \xi \alpha$ e ỏıovouía, e essa relação não apenas se comprova no campo teológico, mas também político. $O$ filósofo da política que vem sustenta que é possível afirmar que "as democracias contemporâneas estão inteiramente fundadas na glória, ou seja, na eficácia da aclamação, multiplicada e disseminada pela mídia além do que se possa imaginar, que o termo grego $\delta o ́ \xi \alpha$ seja o mesmo que designa hoje a opinião pública é, desse ponto de vista, mais que mera coincidência" (AGAMBEN, 2011: 280).

Seguindo indicação de Schmitt, Agamben entende que a expressão da vontade popular, que se manifestava por meio da aclamação na assembleia do povo presente, sobrevive na esfera da opinião pública. A operação de glorificação que sustenta as democracias como governments by consent fica nas mãos dos meios de comunicação.

Além da reflexão sobre a problemática que isso implica - TV, internet são talvez os instrumentos biopolíticos por excelência -, Agamben busca destacar nesse ponto a ação que a $\delta$ ó $\alpha$ continua desempenhando no rol decisivo da política, o consenso e a aclamação, em sua forma moderna. 
O Estado fundado na presença imediata do povo aclamante é resolvido nas formas comunicativas sem sujeito. Trata-se de duas faces do mesmo dispositivo glorioso em suas duas formas: a glória imediata e subjetiva do povo aclamante e a glória midiática e objetiva da comunicação social. Povo-nação (o povo como tal, nas ruas) e povo-comunicação (o povo estatístico, apresentado pela mídia), apesar da diversidade de comportamentos e figuras, são as duas faces da $\delta$ ó $\xi \alpha$, que, como tais, entrelaçam-se e separam-se sem cessar nas sociedades contemporâneas².

Seja na aclamação expressa pelo povo presente ou pelo fluxo dos procedimentos comunicativos, a glória mantém presença decisiva como parceira inseparável do poder. Porém, pergunta Agamben, "por que o poder precisa da glória? Se é essencialmente força e capacidade de ação e governo, por que assume a forma rígida, embaraçosa e 'gloriosa' das cerimônias, das aclamações e dos protocolos? Qual é a relação entre economia e Glória?" (AGAMBEN, 2011: 10).

Agamben representa a glória como o espaço no qual é possível pensar a

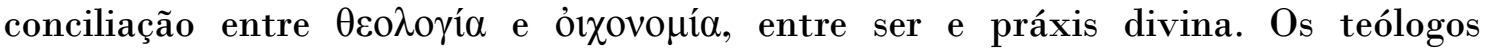
modernos distinguem trindade econômica - ou trindade de revelação - e trindade imanente - ou trindade de substância. A primeira define Deus em sua práxis salvífica, pela qual se revela aos homens. A segunda, a trindade imanente, por sua vez, referese a Deus assim como é em si mesmo.

Encontrar-se aqui, na contraposição entre duas trindades, a fratura entre ontologia e práxis, teologia e economia, que marca constitutivamente a formação da teologia econômica ${ }^{3}$. À trindade imanente correspondem ontologia e teologia, à econômica, práxis e ỏıovouía (AGAMBEN, 2011: 227). Politicamente, a glória articula a relação entre reino e governo. A óıðovo $\mu$ ía glorifica o ser, assim como o ser glorifica a ỏı $\chi v o \mu i ́ \alpha$ - conforme a citação de João. E só no espelho da glória as duas trindades parecem refletir uma na outra, só em seu esplendor ser e ỏıovopía, Reino e Governo parecem, por um instante, coincidir.

A consequência última dessa análise, nas palavras de Agamben é que,

o Reino nada mais é que o que sobra quando se retira o Governo e o Governo é o que resulta da autodestruição do Reino, de maneira que a máquina governamental consiste sempre na articulação dessas duas polaridades, assim também se diria que a máquina teodoxológica resulta da correlação entre trindade imanente e trindade econômica, em que cada um dos dois aspectos glorifica o outro e resulta do outro. O Governo glorifica o Reino e o Reino glorifica o Governo. Mas o centro da máquina é vazio, e a glória nada mais é que o esplendor que emana desse vazio, o kabôd inesgotável que revela e, ao mesmo tempo, vela a vacuidade central da máquina (AGAMBEN, 2011: 231).

\footnotetext{
${ }^{2}$ Nesse entrelaçamento, critica Agamben, os teóricos democráticos e laicos do agir comunicativo correm o risco de se encontrarem lado a lado com os pensadores conservadores da aclamação, como C. Schmitt e E. Peterson, mas esse é precisamente o preço que sempre devem pagar as elaborações teóricas que acreditam em poder prescindir das precauções arqueológicas (AGAMBEN, 2011a: 280).

${ }^{3}$ Embora, como se explicará adiante, essa cisão posso ser remetida à discussão aristotélico sobre vida contemplativa e vida ativa presente na última parte da Ética a Nicômacos.
}

PIN, Alex G. Pensar a biopolítica a partir da teologia: contribuições de Agamben. Griot : Revista de Filosofia, Amargosa-BA, v.18, n.2, p.187-197, dezembro, 2018. 
É precisamente essa vacuidade que fica capturada pelo dispositivo da glória. A glória é uma veste que cobre a nudez do centro da máquina governamental (AGAMBEN, 2011: 213-214).

No pequeno ensaio Nudità (2009), Agamben indaga sobre o conceito de nudez, que é velada pela "vestimenta da glória". Para compreender a nudez enquanto tal é preciso situar-se além da oposição entre nu e velado. A nudez carrega consigo a assinatura teológica que a remete ao problema natureza e graça (AGAMBEN, 2014: 91, 95).

Para a reflexão teológica, "a nudez se dá por assim dizer só negativamente, como privação da vestimenta da graça e como presságio do resplandecente revestimento de glória que os beatos receberão no paraíso" (AGAMBEN, 2014: 57). Para superar esta concepção negativa da nudez, própria da antropologia e soteriologia da cristandade, é preciso encontrar a maneira de concebê-la não como exposição de uma natureza caída, mas como nudez que já não tem nada que desvelar.

Como nas performances de Clarice Niskier, na adaptação do livro A Alma Imoral de Nilton Bonder, a nudez não funciona como segredo ou pressuposto que a vestimenta oculta, mas como nudez que se exibe como aparência, que não é mais que aparência, e que se mostra em sua vacuidade. A nudez é o nada que fica exposto positivamente em sua inquietante falta de significado. É precisamente este nada que constata a inoperosidade constitutiva do homem 4

O homem é o vivente sem obra própria, que a partir da contemplação de sua inoperosidade fica liberado de todo destino biológico ou social.

\begin{abstract}
Compreende-se agora a função essencial que a tradição da filosofia ocidental atribuiu à vida contemplativa e à inoperosidade: a práxis propriamente humana é um sabatismo, que, tornando inoperosas as funções específicas do ser vivo, abre-as em suas possibilidades. Contemplação e inoperosidade são, nesse sentido, os operadores metafísicos da antropogênese, que, libertando o vivente homem de seu destino biológico ou social, destinam-no àquela dimensão indefinível que estamos habituados a chamar de política (AGAMBEN, 2011: 274).
\end{abstract}

A vacuidade central da máquina governamental que a glória oculta é a inoperosidade que nos constitui.

\title{
Política e a teologia
}

Que lugar ocupa a teologia no pensamento agambenano não é pergunta fácil de responder. Colby Dickinson, autor de Agamben and Theology (2011), sugere que de acordo com a leitura que Agamben faz da teologia e filosofia, ele reconhece a existência distinção, mas elas parecem ser duas maneiras de realizar tarefa fundamentalmente semelhante, no fim das contas há pouca diferença entre elas, exceto que a teologia - falando do ponto de vista histórico - entendeu as coisas

\footnotetext{
${ }^{4}$ A religião é fundamentalmente criação de sentido, só depois ela se associa a outros poderes. A religião não dá conta da ausência de sentido, da inoperosidade do homem, por isso, cria-lhe sentido, negando assim sua nudez. A religião reveste o homem de sentido e vela sua nudez, e essa vestimenta tem sofrido processo progressivo de desvelamento (Nietzsche, Heidegger, Agamben).
}

PIN, Alex G. Pensar a biopolítica a partir da teologia: contribuições de Agamben. Griot : Revista de Filosofia, Amargosa-BA, v.18, n.2, p.187-197, dezembro, 2018. 
errado bem cedo, e só agora tem uma oportunidade de assumir sua "missão" de novo (DICKINSON, 2013: 61).

Quando Agamben fala da compreensão paulina do "messiânico" e sua capacidade de derrubar qualquer uma de nossas representações através de uma "divisão da própria divisão", está sinalizando o cerne "teológico" de nossos mais básicos empreendimentos filosóficos (AGAMBEN, 2016: 61-74). Por isso, a mais filosófica obra de Agamben sempre terá seu correlato teológico, assim como seus escritos sobre teologia sempre terão importantes conclusões filosóficas.

Leland de la Durantaye cita, em Agamben, a critical introduction, uma entrevista na qual Agamben afirma que,

\begin{abstract}
Meus livros são confrontações com a teologia. Walter Benjamin escreveu certa vez que "minha relação com a teologia é semelhante à do papel mataborrão com a tinta. $O$ papel absorve a tinta, mas se fosse pelo papel, não restaria uma única gota de tinta'. Isto é exatamente que se passa com a teologia. Estou completamente mergulhado na teologia, porém logo não resta mais teologia, toda a tinta se vai (DURANTAYE, 2009: 369) 5 .
\end{abstract}

A citação convida a indagar a enigmática frase de Benjamin, que Durantaye propõe que se refere simplesmente à onipresença da teologia nas obras benjaminianas, o que é expressamente reconhecido por Benjamin em sua carta de 07 de abril de 1931 a Max Rychner, "E se é que o devo exprimir em uma só palavra: nunca pude buscar e pensar de outra forma, se assim ouso dizer, que não em sentido teológico," (Apud: GAGNEBIN, 1999: 201).

Assim, segundo Durantaye, apelação a Benjamin de Agamben indica que sua declaração pode ser entendida em sentido semelhante. Evidente que questões teológicas não são apenas complementação na obra agambenana, sua erudição nessa matéria deslumbra os estudiosos e comentaristas. Por outro lado, também parece claro que seu pensamento se nutre de permanente e produtivo diálogo entre política e teologia. Porém, essa constatação não é suficiente para explicar o rol em que jogam o intercâmbio entre esses campos.

Não se pode aceitar sem indagar que Agamben concorda com a tese da secularização dos conceitos teológicos nos termos propostos por Schmitt. O próprio Agamben esclarece, "não é preciso compartilhar da tese schmittiana sobre a secularização para afirmar que os problemas políticos se tornam mais inteligíveis e claros se forem relacionados com os paradigmas teológicos" (AGAMBEN, 2011: 251).

Agamben distancia-se de Schmitt porque seu objetivo é radicalmente oposto. Schmidt encontra em sua leitura da secularização a forma de legitimar o poder soberano. A proposta agambenana propõe o contrário: desativar os dispositivos do poder e restituir ao uso comum os espaços que o poder havia confiscado. À operação de secularização é necessário opor-se à estratégia de profanação (AGAMBEN, 2007). Os livros de Agamben são confrontações com a teologia, na qual se opõe a profanação frente a toda forma de sacralização, e a secularização é uma delas.

\footnotetext{
${ }^{5}$ Orig.: My books are confrontations with theology. Walter Benjamin once wrote: my relation to theology is like that of blotting paper to ink. The paper absorbs the ink, but if it were up to the blotting paper, not a single drop would remain. This is exactly how things stand with theology. I am completely steeped in theology, and so then there is no more; all the ink is gone (DURANTAYE, 2009: 369).
} 
É preciso, nesse sentido, fazer uma distinção entre secularização e profanação. A secularização é uma forma de remoção que mantém intactas as forças, que se restringe a deslocar de um lugar a outro. Assim, a secularização política de conceitos teológicos (a transcendência de Deus como paradigma do poder soberano) limita-se a transmutar a monarquia celeste em monarquia terrena, deixando, porém, intacto o seu poder. A profanação implica, por sua vez, uma neutralização daquilo que profana. Depois de ter sido profanado, o que estava indisponível e separado perde a sua aura e acaba restituído ao uso. Ambas as operações são políticas, mas a primeira tem a ver com o exercício do poder, o que é assegurado remetendo-o a um modelo sagrado; a segunda desativa os dispositivos do poder e devolve ao uso comum os espaços que ele havia confiscado (AGAMBEN, 2007: 57-58).

Assim, o objetivo último é a dessacralização de todo aspecto da vida que se encontra capturada pelos dispositivos da teologia, do direito e da economia ao serviço da biopolítica. Cabe perguntar, que tipo de relação se desenrola entre os problemas políticos e dos paradigmas teológicos?

A importância da análise da glória é decisiva para entender essa relação visto que esta desvela um âmbito de indiferenciação entre política e teologia. Convém pensar aqui em algo como um umbral de indistinção sempre operante no que o jurídico e o religioso se tornam indiscerníveis ${ }^{6}$. Tendo em conta que o direito e a teologia são as modalidades da sacralização, ou seja, de captura e separação de aspectos da vida, a indiferenciação da glória permite a Agamben ascender a um espaço no qual é possível pôr em ação sua estratégia de profanação.

O que Agamben procura é desvelar a inevitável verdade encoberta pelo manto da glória acerca da ausência de fundamentação do poder, isto é, o fato de que “doxologias e aclamações são de certo modo um limiar de indiferença entre a política e a teologia. E, assim como as doxologias litúrgicas produzem e reforçam a glória de Deus, as aclamações profanas não são um ornamento do poder político, mas o fundam e justificam" (AGAMBEN, 2011: 251).

Um dos modos possíveis de profanação consiste na reapropriação do messianismo, entendido como categoria mais ligada à política que à religião. Agamben se pergunta se a Igreja finalmente tomará sua oportunidade histórica e reencontrará sua vocação messiânica, pois, do contrário, o risco é que seja arrastada para a ruina que ameaça todos os governos e todas as instituições da terra (AGAMBEN, 2010: 19).

O messianismo que Agamben encontra nas epístolas paulinas (AGAMBEN, 2016) é o modelo para postular uma "nova ontologia da potência" que permitirá articular a proposta política agambenana. As singularidades características da experiência do tempo messiânico e sua facticidade sob a modalidade do ôs $\mu \varepsilon ́$ expressão os traços decisivos de uma ontologia da potência que põe em questão a dimensão política mais própria do homem: a inoperosidade. Essa vida é marcada por um senso especial de inoperosidade que de certa maneira antecipa no presente o sabatismo do Reino: o òs $\mu \varepsilon ́$, o "como se não".

\footnotetext{
${ }^{6}$ Aqui entra o exemplo da análise feita por Agamben dos textos diosinianos. O mais acabado amalgama entre teologia cristã e política.
}

PIN, Alex G. Pensar a biopolítica a partir da teologia: contribuições de Agamben. Griot : Revista de Filosofia, 
Assim como o Messias cumpriu e, ao mesmo tempo, tornou inoperosa a lei - o

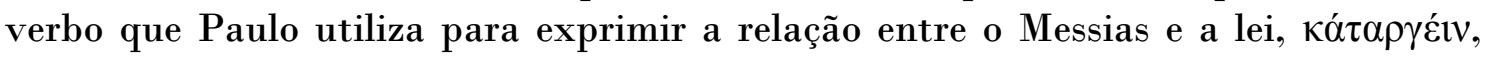
significa literalmente tornar inoperoso -, assim também o ô $\zeta$ $\mu$ ć conserva e, ao mesmo tempo, desativa no tempo presente todas as condições jurídicas e todos os comportamentos sociais dos membros da comunidade messiânica: "Isto então vos digo, irmãos: o tempo se contraiu; o que resta é que os casados sejam como se não ô $\zeta \mu \varepsilon$ - fossem casados, os que choram como se não chorassem, os que se alegram como se não se alegrassem, os que compram como se não possuíssem e os que usam o mundo como se não usassem. De fato, a figura deste mundo passa" (1 Cor 7, 29-32 Apud AGAMBEN, 2014: 270).

A vida messiânica é a impossibilidade da vida de coincidir com uma forma predeterminada, a revogação de todo bios para abri-lo para a zoé tô̂ Iesoû. E a inoperosidade que aqui acontece não é simples inércia ou repouso, mas é, ao contrário, a operação messiânica por excelência (AGAMBEN, 2011: $272)$.

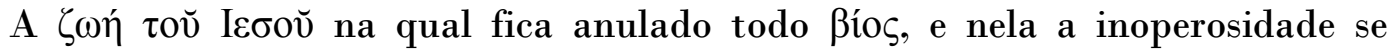
constitui na obra mais própria do homem, se identifica com certos traços da

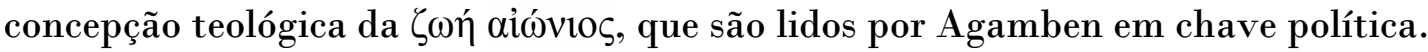

"Zoé aiónios, vida eterna, é o nome desse centro inoperoso do humano, dessa "substância" política do Ocidente que a máquina da economia e da glória busca continuamente capturar em seu próprio interior" (AGAMBEN, 2011: 274).

Esta inoperosidade essencial da vida eterna, que é posta em prática temporalmente na vida messiânica, é isolada e controlada pela máquina da economia e da glória, que a substitui por uma doutrina da vida gloriosa. Por um dispositivo que já nos é familiar, a doutrina da vida messiânica acaba sendo substituída pela doutrina da vida gloriosa, que isola a vida eterna e sua inoperosidade em esfera privada. A vida, que tornava inoperosa toda forma, agora se torna ela mesma forma na glória. Impassibilidade, agilidade, sutileza e clareza tornam-se assim as características que identificam, segundo os teólogos, a vida do corpo glorioso (AGAMBEN, 2011: 272).

\section{A vida terrena e a vida eterna}

O ensaio de 2009, Nudità, apresenta alguns delineamentos que permitem vislumbrar a potencialidade política da inoperosidade da vida eterna. Agamben indaga a respeito da doutrina da vida gloriosa perguntando-se pela ideia de corpo glorioso e propõe utilizar esta categoria para pensar a figura e os possíveis usos do corpo humano como tal (AGAMBEN, 2014: 142).

O corpo glorioso se caracteriza por ser corpo ostensivo, cujas funções fisiológicas não são executadas, senão simplesmente exibidas. No corpo glorioso, foi pensado pela primeira vez a separação entre o órgão e sua função fisiológica. Entretanto, a possibilidade de outro uso do corpo, que essa separação deixava 
entrever ficou inexplorada. Em seu lugar, colocou-se a glória, concebida como o isolamento da inoperosidade em uma esfera especial (AGAMBEN, 2014: 144).

A glória funciona como o dispositivo que captura e oculta a inoperosidade essencial do ser humano. É necessário, então, liberar a vida eterna da ideia de glória, de sua função de glorificação, para poder pensar a inoperosidade como "a passagem ou o 'abre-te, sésamo' de um outro uso possível". A glória, assim, não é senão a separação da inoperosidade numa esfera especial, a saber, a da liturgia ou culto. Desse modo, aquele que era apenas o limiar que permitia o acesso a um novo uso transforma-se em condição permanente.

Um novo uso do corpo só é possível, portanto, se "se arrancar a função inoperosa da sua separação, e apenas se se conseguir fazer coincidir num único lugar e num único gesto o exercício e a inoperosidade, o corpo econômico e o corpo glorioso, a função e a sua suspensão. Função fisiológica, inoperosidade e novo uso existem no único campo de tensão do corpo e não se deixam separar dele" (AGAMBEN, 2014: 146).

A inoperosidade revela a potência como traço decisivo da existência humana. Potência que é, simultaneamente, possibilidade de ser e não ser. Em outro brevíssimo ensaio do mesmo livro, Agamben reflete sobre o sentido político desse não ser como poder não fazer. A operação do poder político se caracteriza por atuar tanto sobre o que os homens podem fazer como sobre o que não podem fazer. É este segundo aspecto o que interessa Agamben - assim como o interessou a inversão do poder do soberano de deixar viver e fazer morrer em fazer viver e deixar morrer. O dispositivo econômico-biopolítico, que se manifesta no triunfo das leis de mercado, faz crer ao homem que tudo é possível.

Separado de sua impotência, privado da experiência do que não pode fazer, o homem de hoje se crê capaz de tudo e repete sua jovial 'não há problema' e sua irresponsabilidade 'posso fazer', precisamente, quando, ao contrário, deveria dar-se conta de que está entregue em medida inaudita à forças e processos sobre os quais perdeu completamente o controle. Nada nos faz tão pobres e tão pouco livres como este estranhamento da impotência.

Aquele que é separado do que pode fazer ainda pode resistir, pode não fazer. Ao contrário, aquele que é separado de sua impotência perde, principalmente, a capacidade de resistir. E como é somente a ardente consciência do que não podemos ser que garante a verdade do que somos, assim, é apenas a visão lucida do que não podemos ou podemos não fazer que dá consistência ao nosso agir (AGAMBEN, 2014:73)

O corpo glorioso não é um outro corpo, mais ágil e belo, mais luminoso e espiritual: é o mesmo corpo, no ato em que a inoperosidade o retira do encanto e o abre a um novo possível uso comum (AGAMBEN, 2014: 146). A pergunta frente ao diagnóstico biopolítico não é pelo que fazer, mas pelo que não fazer. Agamben convida a pensar a resistência a partir dessa experiência de inoperosidade que a ideia de vida eterna põe em jogo.

A resistência que se manifesta como clara consciência da situação. Para poder entender que a pergunta pertinente é que posso não fazer, é preciso compreender a radicalidade do diagnóstico biopolítico. Toda proposta que se apresente em termos de um fazer corre o risco de ser reabsorvida pelos dispositivos biopolíticos da religião 
capitalista: o consumo e o espetáculo. "Se, conforme foi sugerido, denominamos a fase extrema do capitalismo que estamos vivendo como espetáculo, na qual todas as coisas são exibidas na sua separação de si mesmas, então espetáculo e consumo são as duas faces de uma única impossibilidade de usar" (AGAMBEN, 2007: 64).

Os novos usos que a contemplação da inoperosidade faz possível deverão ser pensados sob a modalidade do poder não fazer como estratégias de profanação frente à impossibilidade de uso custodiado por aqueles dispositivos. Agamben opõe à maquinaria biopolítica as características dessa vida que a biopolítica pretende controlar, isto é, a própria vida é incompatível com o controle biopolítico.

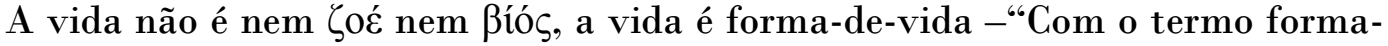
de-vida, entendemos uma vida que não pode ser separada de sua forma, uma vida na qual não é possível isolar e manter distinto algo como uma vida nua" (AGAMBEN, 2014: 264), - não é vida gloriosa, mas vida eterna; não se caracteriza principalmente por produção, mas pela inoperosidade. É, precisamente, no permanecer fiel a esta inoperosidade constitutiva que se encontra a resistência mais radical. A ambiciosa aposta de Agamben consiste em delinear uma resistência de acordo com a ontologia da potência, ou seja, uma política frente a todo ato da inoperosidade frente a toda obra; o que não implica outra coisa que reconhecer a absoluta irredutibilidade da justiça ao direito e da liberdade à economia.

É realizável uma política semelhante ou trata-se da expressão de um desejo que tão-somente pode atuar como ideia reguladora? Seria apressado dar resposta definitiva sobre esta questão, sobretudo, quando o que se está interrogando é o atuar e a prioridade mesma do ato. Apenas a diligente analise de Homo Sacer IV, 1 e IV, 2 - respectivamente, Altissima Povretà (2011) e L'uso dei Corpi (2014) - poderia sugerir resposta adequada. 


\section{Referências}

Agamben, G. (2007) Profanações. Trad. Selvino J. Assmann. São Paulo: Ed. Boitempo.

AGAMBEN, G. (2010) La Chiesa e il Regno. Roma: Ed. Nottetempo.

AGAMBEN, G. (2011) Homo Sacer II, 2, O Reino e a Glória, Uma Genealogia Teológica da economia e do Governo. Trad. Selvino J. Assmann. São Paulo: Ed. Boitempo.

Agamben, G. (2014) Nudez. Trad. Davi Pessoa. São Paulo: Ed. Autêntica.

AGAMBEN, G. (2016) O tempo que resta, Um comentário à Carta aos Romanos. Trad. Davi Pessoa e Cláudio Oliveira. São Paulo: Ed. Autêntica.

DICKINSON, C. (2013) Agamben e a estreita relação entre filosofia e teologia. In: Revista do Instituto Humanitas Unisinos, No 427 - Ano XIII, São Leopoldo-RS. Disponível

http://www.ihuonline.unisinos.br/media/pdf/IHUOnlineEdicao427.pdf acesso 27.07.2016

DURANTAYE, L. (2009) Agamben, a critical introduction. Stanford: Ed. Stanford University Press.

GaGNEBIN, J.M. (1999) Teologia e Messianismo no pensamento de W. Benjamin. Revista de Estudos Avançados. Vol.13, Nº 37, São Paulo.

Autor(a) para correspondência: Alex G. Pin, Universidade de Brasília, Instituto de Ciências Humanas, Campus Universitário Darcy Ribeiro, CEP 70910-900, Brasília - DF, Brasil. alexgpin@live.com 